\title{
$\mathrm{XV}$. Some observations on the migration of birds
}

\section{Edward Jenner M.D. F.R.S.}

To cite this article: Edward Jenner M.D. F.R.S. (1824) XV. Some observations on the migration of birds, Philosophical Magazine Series 1, 64:316, 91-102, DOI: $10.1080 / 14786442408644562$

To link to this article: http://dx.doi.org/10.1080/14786442408644562

曲 Published online: 29 Jul 2009.

Submit your article to this journal $2 \pi$

Џ Article views: 2

Q View related articles $₫$ 
its origin from this source, as neither the winter mew nor any of its congeners ever make any stop, and are rarely seen in his neighbourhood.

Carr End.

William Fothergill.

XV. Some Observations on the Migration of Birds. By the late Edward Jenner, M.D. F.R.S.; with an Introductory Letter to Sir Humphny Davy, Bart. Pres. R.S., by the Rev. G. C. JENner.

[Concluded from p. 60.]

I PROCEED now to make some observations on another kind of migration, directly opposite to the foregoing, namely, the return of the spring migrators to their respective homes.

The great disproportion in numbers between those species of birds which quit the country in summer, and those that leave it at the autumnal season, has led naturalists to lose sight of the early migrators, and to confine their reflections on the subject to the late ones only. Hence the common observation, that they are all driven off through a failure of food or a cold temperature of the air. But seeing that many of them disappear in the summer season, when food is placed before them in the greatest plenty, we must seek for some other cause. If we examine what is now going forward in the animal economy, dissection will point out a change in the testes and ovaria, the very opposite to that which took place in the spring. These parts now begin to shrink*, the disposition for raising a further progeny ceases, and the nuptial knot is dissolved. What inducement have they to stay longer in that country where, I think, it clearly appears their chief object is to multiply their species? This being now effected, they retire to different parts of the globe, doubtless better suited to their general dispositions and wants, when disengaged from parental duties. In many of the migrating species, indeed in the far greater number, the disposition for further incubation, and the season for their procuring a further supply of insect food, cease at the same time. It is pretty evident from the habits of the cuckoo and the swift, that quit us in the summer as soon as their nesting is at an end, that swallows, martins, and those birds that disappear in the autumn, would depart at an earlier season, even though their supplies were to continue, if the rearing of their young were perfected. Indeed, as has been before observed, so strong does this propensity

* I examined a female cuckoo the first week in July, and found the oviduct shrivelled, and all the eggs disposed of. 
now and then appear, that it overcomes even the obligation of rearing their young when hatched late in the season, and they are sometimes left in a callow state to perish in their nests. This premature departure, probably arises from a reverse of that stimulus which occasions the too early migration of the spring birds, as has been noticed in a former part of this essay, namely, a change which takes place in organization.

One of the most singular occurrences in the history of migration, is the mode of departure of the young birds from the country where they were produced. It may be conceived that the bird which had once crossed the Atlantic, or any other ocean, might have sometbing impressed upon it that should prove an inducement to its return; but this cannot be an incitement to the young one. The identical bird, which but a few weeks before burst from the shell, now unerringly finds, without any apparent guide, a track that leads it safely to the place of its destination, perhaps in many instances over the widest oceans.

It is well known, that those birds which incubate several times in the course of one summer, forsake their first broods when they no longer require their protection: and being now alienated, they cannot, in their parents, find the guides that conduct their course. As swallows and martins congregate* prior to their departure from us, it may be said that their young, though discarded, may mingle with the common flock, and in this particular instance $I$ am ready to admit that it is probable they may do so; but there are many migrating birds that never either associate with swallows and martins, or join together in flocks, as the nightingale, redstart, and indeed the far greater number. As a striking proof that the parent bird cannot possibly be the guide, in one instance at least, we may point out the cuckoo, whose offspring finds a distant shore in perfect safety, although it could never know the parent to whom it was indebted for existence, and though its existence in numberless instances must have taken place even after the departure of the parent. For the old cuckoos invariably leave us early in July, when many of their eggs are yet unhatched in the nests of those small birds to whose fostering care they

* Swallows and martins congregate on the sunny sides of buildings for the sake of warmth, and not, as it is generally supposed, to hold a kind of consultation previous to their final departure. In the wet summer of 1821 , when the air was unusually chilled by the long continued rains, they were observed to assemble, during some intervals of sunshine, for several successive mornings, as early as the middle of July; and in the present year (1822) I remarked the same on some mornings that wcre unseasonably cold about the middle of August. 
are intrusted. Compared with quadrupeds, and some other animals, birds may be considered as acquiring the adult state at an early period, and the young bird, at the time of its leaving us, may be looked upon as possessing power equal to the old one in procuring food, velocity of flight, \&c. The parent bird, from having lost that stimulus by the subsiding of the testes and ovaria, which urged it to incubation and detained it here, is now reduced to a condition similar to that of its offspring, both falling into the same habits, and remaining in the same state with respect to organization, until the returning calls of nature urge them to quit that country again to which they are now about to depart.

II.

\section{Winter Birds of Passage.}

“We have, 'tis hoped, made it pretty evident that summer birds of passage come to and depart from us at certain seasons of the year, merely for the sake of a more agreeable degree of warmth, and a greater plenty of food; both which advantages they procure by an alternate change of climate; but the migration of winter birds of passage, and particularly of fieldfares and redwings, is much more difficult to be accounted for, there being no such apparent necessity either on the score of food or climate, for their departure from us."-Mr. Catesby, Phil. Trans. No. 483.

The winter birds of passage, as they are commonly called, begin to take their leave of us about the same time that the spring migrators are taking wing to pay us their annual visit. As the latter appear among us in gradual succession, so in like manner the former disappear. They are both actuated by the same impulse, the former in leaving, and the latter in coming to this country, namely, the enlarged state of the testes and ovarium. As soon as the stimulus becomes sufficiently felt, they quit their homes in quest of a country better suited to their intended purpose than their own.

That a want of food cannot be the inducement, must be obvious to the slightest observer. When the redwing and fieldfare quit this country, it abounds with that food which they prefer to any other; and at this time they are in the finest condition; the redwings often enjoying their plenty by assembling together on trees, and there uniting their feeble voices, make no unpleasant song*.

* The same thing happens through the winter, whenever the weather has long continued so mild as to allow them plenty of insert food. The starling (and some other birds which have a short note and weak voice) unites with its companions in the spring, and forms a similar concert. 
The winter birds (the females at least) may be said to seek a better accommodation, upon the same principle as the poor woman who quits her cottage for the comforts of a Lying-in Hospital. Here, both herself and suckling are for a while supported in that peculiar way which their situations at that time require. For this reason, conceiving it will tend to lessen confusion, I choose to call this country the home of the winter birds (though not natives), and the countries from whence they come, the home of the summer birds, looking upon the latter merely as visitors; and let it be recollected how soon the visits of some of them are paid; for, being governed by an unerring principle, they stay to accomplish one great design only, that of rearing their young, and then return.

The countries to which many of the winter birds retire not being very far distant, are better known to us than those to which the summer birds migrate; but I must forbear entering into an inquiry upon this subject, as remote from the design of this paper; and indeed it may be thought 1 have already, in some instances, digressed too widely from my original purpose.

The migration of the winter birds is less distinctly marked than that of the spring migrators. The snipe, the wild-duck, the wood-pigeon, breed here in considerable numbers; the two latter indeed, particularly the wood-pigeon, are so numerous in summer, that we should hardly be reminded of the migration, did they not pour in upon us in such immense flocks in the winter. They are accompanied by the stockdove, which I have never known to breed here. The homebred wild-ducks are ensily distinguished by the men who attend decoy-pools, by the meanness of their plumage, when compared to the brightness of those birds which come from abroad. The former are taken some weeks earlier than the latter.

The most conspicuous among the winter migrating birds are the redwings and fieldfares. These are regular and uniform in their appearance and disappearance, and I believe never risk the trial of incubation here, at least I never could hear of a single instance. The food of these birds has in the works of every naturalist I have ever had access to, who had written on the subject, been pointed out as the haw, the fruit of the white-thorn*.

This is an error that has long wanted a correction; for in open weather they take them in very scanty quantities, and

* " The principal food of these birds, while with us, is the fruit of the white-thorn, or haws, which hang on our hedges in winter in prodigious plenty."-Phil. Trans, vol. xliv, p. 435. 
feed on the ground on worms and such insects as they can find. Although repeated examinations of the contents of the stomach have afforded the best proof of this, yet there is scarcely any need of calling in its aid in the present instance, as we may be convinced of the fact, by seeing them in flocks feeding on the ground in open fields and meadows. I do not deny their taking the haw and other vegetable food from the hedges; but they do it in so sparing a way, that I have re.marked, that redwings and fieldfares died through hunger during the long continuance of frosty weather, while the haws on the hedges were by no means deficient. The occasional departure of these and some other winter birds during a long continued frost, must be very obvious. The greater number disappear soon after its commencement, if it sets in very severely: some few are always left behind and are soon starved, if not fortunately relieved by a thaw. 'Those that are driven to this necessitous migration, probably pursue a track that quickly leads them out of the reach of frost. Of these flights I shall produce instances, which render it probable that they are able even to outstrip its course.

The approach of intense frost is often to a certainty made known to us by the appearance of a numerous tribe of waterbirds, some of which are rare, and seldom show themselves here on any other occasion. We commonly see them three or fotir days prior to the setting in of very severe frosty weather. This was manifest at the latter end of the year 1794, at the coming on of the severe season that ensued. In the river Severn, about a mile and a half to the westward of this place, were seen and taken many species of water-birds, that generally confine themselves to the more northern regions. Far more pleasant is it to see during the continuance of hard forst, the return of those birds which had left us at the beginning. These are pleasant omens, and most certainly forebode a thaw. The following example shows how soon they catch the first opportunity of again seeking those countries from which they were so lately driven by necessity. The day preceding the thaw, the frost being then intense, a gentleman who was shooting observed a large flock of fieldfares, birds that are extremely common here in milder weather. They were as much untamed as if no frost had appeared in our island. He had the good fortune to shoot one of them, which was brought to me. I found it as fat and plump, and in every respect in as good condition, as if it had remained here undisturbed, and had found provision in the greatest plenty, though it was without a particle of food in its stomach. Its last meal was digested; and the frost still remaining, it could find no 
food for its present support. Now it is very obvious that this bird, and its companions, must have taken a long flight, and probably in a very short space of time; for the intense frost, that was of such duration and so severely felt here, extended far into the more southern parts of Europe, beyond which they must have resorted for that plenty of food which gave plumpness to the one I examined, and doubtless to the whole flock, from their appearing so wild and vigorous. It clearly appears, that in their flight they exceeded the progress of the thaw, as the northern birds did that of the frost. This thaw, though it was again succeeded by frost, came on very rapidly, and occasioned, by the sudden melting of the snow, those destructive inundations through the kingdom, that will not readily be forgotten.

This account of the fieldfare sets the fact of migration, though from an accidental cause, beyond the reach of doubt. There was no support for it here; the ground was deeply covered with snow, and the intense frost, by its long duration, had destroyed every thing that could afford it succour; it must therefore have taken a long flight from this country, and returned to it again at the approach of temperate weather.

Having already made so many digressions, I cannot add another without offering an apology; but as there is something so like providential design in the order in which the song birds chaunt out their warblings during a long summer's day, I trust the Society will pardon my laying before them the following observations on the subject.

We must observe, that nature never gives one property only to the same individual substance. Through every gradation from the clod we tread upon to the glorious sun which animates the whole terrestrial system, we may find a vast variety of purposes for which the same body was created. If we look on the simplest vegetable, or the reptile it supports, how various yet how important in the economy of nature are the offices they are intended to perform! The bird, I have said, is directed to this island at a certain season of the year to produce and rear its young. This appears to be the grand intention which nature has in view; but in consequence of the observation just made, its presence here may answer many secondary purposes; among these I shall notice the following. The beneficent author of nature seems to spare no pains in cheering the heart of man with every thing that is delightful in the summer season. We may be indulged with the company of these visitors, perhaps, to heighten, by the novelty of their appearance, and pleasing variety of their 
notes, the native scenes. How sweetly, at the retum of spring, do the notes of the cuckoo first burst upon the ear; and what apathy must that soul possess, that does not feel : soft emotion at the song of the nightingale (surely it must be " fit for treasons, stratagems, and spoils")! and how wisely is it contrived that a general stillness should prevail while this heavenly bird is pouring forth its plaintive and melodious strains, - strains that so sweetly accord with the evening hour! - Some of our foreign visitors, it may be said, are inharmonious minstrels, and rather disturb than aid the general concert. In the midst of a soft warm summer's day', when the martin is gently floating on the air, not only pleasing tis with the peculiar delicacy of its note, but with the elegance of its meandering; when the blackeap is vying with the goldfuch, and the limet with the woodlark, a dozen swilts rush from some neighbouring battlement, and set up a most discordant screaming. Yet all is perfect. The interruption is of short duration, and without it, the long continued warbling of the softer singing birds would pall and tire the listening ear with excess of melody, as the exhilarating beams of the sun, were they not at intervals intercepted by clouds, would rob the heart of the gaiety they for a while inspire, and sink it into languor. There is a perfect consistency in the order in which nature seems to have directed the singing birds to fill up the day with their pleasing harmony. To an observer of those divine laws which harmonize the general order of things, there appears a design in the arrangement of this sylvan minstrelsy. It is not in the haunted meadow or frequented field we are to expect the gratification of indulging ourselves in this pleasing speculation to its full extent; we must seek for it in the park, the forest, or some sequestered dell, half inclosed by the coppice or the wood.

First the robin, and not the lark, as has been generally imagined, as soon as twilight has drawn the imperceptible line between night and day, begins his lonely song. How sweetly does this harmonize with the soft dawning of day! He goes on till the twinkling sunkeams begin to tell him his notes no longer accord with the rising scene. Up starts the lark, and with him a variety of sprightly songsters, whose lively notes are in perfect correspondence with the gaiety of the morning. The general warbling continues, with now and then an interruption, for reasons before assigned, by the transient croak of the raven, the screaming of the jay and the swift, or the pert chattering of the daw. The nightingale, unwearied by the vocal exertions of the night, withdraws not proudly by day from his inferiors in song, but joins them in the general harFol. 64. No. 316. Alig. 1824. 
mony. The thrush is wisely placed on the summit of some lofty tree, that its lond and piercing notes may be softened by distance before they reach the ear, while the mellow blackbird seeks the inferior branches. Should the sun, having been eclipsed with a cloud, shine forth with fresh effulgence, how frequently we see the goldfinch perch on some blossomed bough, and hear his song poured forth in a strain peculiarly energetic; much more sonorous and lively now than at any other time; while the sun, full shining on his beautiful plumes, displays his golden wings and crimson crest to charming advantage! The notes of the cuckoo blend with this cheering concert in a perfectly pleasing manner, and, for a short time, are highly grateful to the ear; but, sweet as this singular song is, it would tire by its uniformity, were it not given in so transient a manner. At length, evening advances-the performers gradually retire, and the concert softly dies away. The sun is seen no more. The robin again sets up his twilight song, till the still more serene hour of night sends him to the bower to rest. And now to close the scene in full and perfect harmony, no sooner is the voice of the robin hushed, and night again spreads a gloom over the horizon, than the owl sends forth his slow and solemn tones. They are more than plaintive, and less than melancholy, and tend to inspire the imagination with a train of contemplations well adapted to the serious hour. Thus we see that birds, the subject of my present inquiry, bear no inconsiderable share in harmonizing some of the most beautiful and interesting scenes in nature.

But let me here remark-how ill would the singing of birds agree with the general appearance of winter-the leafless tree, -the snowy mead,--the frozen rivulet! Yet it must be noticed here, that these rigors, in the midst of this dreary season, are sometimes suddenly softened, and a temperate state of the air succeeds. We are then so enlivened by the transition from extreme cold to. a temperature comparatively warm, that we can listen with pleasure to the enfeebled notes of some of the song birds. How admirable the contrivance! There are several birds which have no continued flow of notes, but a kind of chirp only, consisting of some variety of sounds. During a long continued frost, the earth affords many of the feathered tribe so scanty an allowance that they preserve themselves with difficulty from perishing; a sudden thaw takes place, $\rightarrow$ plenty at once appears, and every crop is filled. 'Tis then we see the redwing and starling assemble in large flocks among elms and apple trees, and, by uniting their voices, produce a song not in the least discordant, but, on the contrary, extremely harmonious. At this time the thrush, and even 
the blackbird, will occasionally afford us a transient song; but it may be observed, that the notes of these birds are rather to be considered as plaintive, than lively. The lark, too, will sometimes mount in the air, beguiled, as it were, by the faint rays of a wintry sun, but his notes are then as poor and feeble as the beams that call him forth. The robin indeed cheers us with his song during the whole of the winter, unless driven off by intense frost, and is the only bird I know, whose notes at this time would fully accord with our feelings, so perfectly do they mingle with the surrounding order of things. The goldfinch, were he now to open his full song upon us, would be as appalling as tones of the owl in the midst of a fine summer's day.

\section{III.}

Mr. John Hunter, my late valued friend and honoured preceptor, under whose roof I first caught a gleam of that light which so successfully conducted him through the obscure paths of nature, first demonstrated the different sizes of the testes of birds at different seasons of the year. On a further investigation of this subject, a fact presented itself to me, which may not be unworthy of the attention of this Society, and, as it is in some measure connected with the preceding observations, I have taken the liberty of annexing it.

In those birds that remain but a short time paired with the female, there appears a vast disproportion in the size of the testes, compared with those that live in the connubial state much longer. The cuckoo and the swift point out the fact most obviously. The common brown wren, which remains united with its female from the early part of spring until the autumn, exhibits testes very far exceeding in size either those of the cuckoo or the swift. The cuckoo, although a polygamist, may here be considered in the same point of view as the birds that pair. The time which he devotes to the female being so very short, more so indeed by some weeks than even that of the swift, the testes are formed extremely small in proportion to the size of the bird. I never saw them exceed in size the common vetch, while those of the wren were full as large as a common sized garden pea. The medium weight of the cuckoo is about four ounces and a half, that of the wren but little more than three drachms*. The testes of the swift,

* Ornithologists might easily have given us the weight of a bird with greater precision, by divesting the stomach of its contents previous to the bird being weighed. For example: how very different must the weight of the owl be, which, in its nocturnal flights, had the luck to pick up a mole or two, compared with that which had met with opposite fortune; or of the falcon, that had picked the bones of a leveret, or of the one that was killed witl an empty stomach! 
which assume a singular oblong shape, somewhat exceed the cuckoo's in bulk, though not so large as those of the wren. I have selected the wren as an example for this comparison, on account of its diminutive size. The testes of all those birds which are capable of producing young more than once in the breeding season, become tumid, as far as I have seen, in the same proportion as those of the wren.

As there are many birds, which, if unmolested, produce but one nest of young ones in the course of the season, it may be asked, why nature should cause as great an enlargement of the testes in these, as those which breed more than once; and why they should exceed in bulk those of the cuckoo or the swift? The answer, I presume, is obvious. Should any ill accident befall the nestlings of the swift when advancing to maturity, the injury would be irreparable, the parent bird being destined to quit the country before another offspring could be reared. The cuckoo is in the same predicament; but the wide dispersion of its young ones (being placed singly in the nests of other birds) gives them such security as almost to preclude the possibility of their general destruction*. But it is not so with those birds which make a longer stay; should similar accidents befall them, they can repair their losses. Nature, as long as incubation could serve their purposes, would keep in accumulation of the proper powers in store, which, in the case of the cuckoo and swift, would be entirely useless.

Whether there be a regular gradation in the size of the testes (that of the bird itself being considered) throughout the whole race, in proportion to the time taken up in pairing, I cannot determine, not having had an opportunity of subjecting the matter to a full investigation. However, I thought the fact already shown of sufficient importance in natural history, to be worthy of communication, as it forms a kind of sequel to Mr. Hunter's paper on the subject.

With due deference to the late Dr. Darwin, I am inclined to think that the opinion he set forth respecting the pairing of cuckoos, was taken up hastily, and that the birds which his friend saw were not cuckoos feeding their nestlings, but goatsuckers, whose mode of nesting corresponds with the relation given, and whose appearance might be mistaken for them by one not perfectly conversant with the plumage and the general

* May not this be offered as another reason why its eggs and young ones are intrusted to the fostering care of so great a variety of birds? It could not have time, during its short stay, to rear so large a progeny; and by no other means could it have placed its numerous brood so much out of the way of danger, 
appearance of cuckoos when on the wing. Is it probable that the cuckoo, which is invariably a polygamist, and never pairs, nests, or incubates in this part of the island, should fall into opposite habits in another part?

To recapitulate the substance of my observations. I have first adduced some arguments in support of migration, the fact itself not being generally aimitted by naturalists of celebrity, and also against the hypothesis of a state of torpor, or what may be termed the hybernating system. I have represented that the swallow tribe, and many other birds that absent themselves at stated periods, return annually to the same spot to build their nests; and at the same time that any inference drawn fiom this fact in support of a state of torpor, would be fallacious upon physiological principles. That certain periodical changes of the testes and ovaria, are the inciting causes of migration. I have stated many facts, hitherto, I believe, unnoticed, chiefly with respect to the cause which excites the migrating bird, at certain seasons of the year, to quit one country for another, viz. the enlargement of the testes in the male, and ovaria in the female, and the need of a country where they can for a while be better accommodated with succours for their infant brood, than in that from which they depart. It is also attempted to be shown that their departure from this country is not in consequence of any disagreeable change in the temperature of the air, or from a scarcity of their common food, but the result of the accomplishment of their errand, i.c. the incubation, and rearing of their young, and the detumescence of the testes and ovaria. That successive arrivals of migrating birds are attributable to the progressive development of the generative system in the male and female; that progressive developments are wise provisions of nature; that premature arrivals and departures are frequently to be accounted for on the same principle; that the departure of the spring migrators is owing to a change in the testes and ovaria, the very spposite to that which took place in the spring; that the departure of the young birds is not guided by the parent, but the result of an unknown principle.

In the second part of this paper, some observations are made on the winter birds of passage; that they quit their homes (this country) in spring, in quest of a country better suited to their intended purpose than their own; that they are actuated by the same impulse in quitting this country that causes the spring birds to come to it, and that want of food cannot be the inducement; that the emigration of the winter birds is less complete than that of the others (the spring migrators); that some species breed here, especially the wildduck 
duck and wood-pigeon; that the redwings and fieldfares are the most regular and uniform in their appearance and disappearance, and most probably never risk the trial of incubation here*; that they quit the country temporarily in severe and long-continued frost through want of food, and return to it again at the approach of more temperate weather; that the arrival of water-birds forebodes the approach of intense frost, the usual return of the winter-birds, a thaw; that examinations of the latter prove them to have taken long flights before their return, and sets the fact of temporary migration beyond the reach of doubt.

1 have then made a digression, and introduced some observations on the singing of birds; and in a third part, given some additional particulars respecting the different sizes of the generative organs of birds, as they appear at different seasons of the year.

\section{Introduction to the Seventh Section of Bessel's Astrono- mical Observations.}

HAVING explained in the preceding section the means which I have employed to give all desirable certainty to the observations for determining right ascensions, I now communicate the methods which I have pursued for ensuring an equal degree of accuracy to the declinations. It was necessary for this purpose to examine both the instrument itself and the refraction; for, if the hope of advancing further than has hitherto been done, by an accurate knowledge of the instrument, be well founded, the refraction must likewise be better determined than by preceding observations. It is well known that the refractions hitherto used in this observatory, have been derived by me from Bradley's observations; but the meridian circle of Reichenbach possesses considerable advantage over the mural quadrant both by the accuracy of single observations, and the possibility of discovering all constant errors; and besides, it admits of any examination which the observer may in future deem necessary; whereas for the Greenwich quadrant the existing number of facts recorded by Bradley in his observations is for ever closed.

I will endeavour to give a general view of the course of this investigation before I enter into the detail of every part. The errors of the instrument which I have determined so as to be

* I must be understood by the word "here," to mean that part of Gloucestershire under my own observation. 